\title{
HIGH-STAKES TESTS WRITING COMPONENT: WHAT MAKES IT DIFFERENT FROM WRITING IN GENERAL
}

\author{
Davoud Behrouz ${ }^{1}$, Reza Vahdani Sanavi ${ }^{1}$, Ali Safivand ${ }^{2}$, Abdolvahab Khademi- \\ Shamami ${ }^{3}$
}

${ }^{1}$ Islamic Azad University - Roudehen Branch (IRAN)

${ }^{2}$ Islamic Azad University - Shahre Qhods Branch (IRAN)

${ }^{3}$ Iran University of Science \& Technology (IRAN)

davoudbehrouz@yahoo.com, vahdani.reza@gmail.com, ali.safivand@gmail.com, vahab.khademi@gmail.com

\begin{abstract}
What is it that one needs to know in a language to be able to write it? What challenges do students meet when they try to write for a high-stakes test? How should the teacher react to students taking such highstakes tests as TOEFL or IELTS? Or yet, does knowledge of all these things for both the teacher and the learner contribute significantly to their successful enhancement of knowledge and subsequent better performance? These are only a few of the problems that students who wish to sit for these exams should deal with. Basically, what the researchers would like to find out is what challenges high-stakes tests candidates face. Some scholars (Brown, [1]; Nunan, [2]) have mentioned what makes writing difficult but none have mentioned whether or not there is anything which adds to the difficulty of the high-stakes tests. What other challenges do students meet when taking the TOEFL or IELTS exam? To this end, some 67, IELTS and TOEFL students were asked to fill out a questionnaire to find out what challenges they have when they write in English, in general and what makes high-stakes writing component difficult, in particular. Twenty four of the participants were then interviewed to have an in-depth analysis of their challenges. The findings, among others, suggest that high-stakes tests exert so much pressure on the candidates. Since they believe their future rests in their performance on such tests, they might not even be able to evince their actual knowledge of the language.
\end{abstract}

\section{INTRODUCTION}

What are the students required to know in a specific language to write effectively? Do students like the writing itself and also the way that their teachers deal with their mistakes? What are their major problems? Is their attitude entirely based on the strategies that their teachers adopt? What is the reaction of the teachers towards students taking very important tests such as TOEFL or IELTS? These are just some of the problems with which the students are obsessed.

Winer [3] suggested that students will improve if they are aware of such problems as what the test measures, what the different tasks are in writing, and how their writing is assessed. Moreover, the researchers are concerned about the challenges to which highly crucial test takers respond. Some scholars (Brown, [1], Nunan, [2]) dealt with the factors making the task of writing difficult, but none of them mentioned whether there is anything contributing to difficulty of writing. What problems do students face while taking tests?

\section{REVIEW OF THE RELATED LITERATURE}


These problems will cause teachers to employ some strategies to improve their students' skills. Winer [3] followed some strategies to some students with negative attitude, but not with positive ones. The researchers try to figure out whether such strategies are useful for students who have a positive attitude.

It is important to understand that the TOEFL or IELTS candidates attend their classes with excessive anxiety and dread. Even some of them shed tears on the first session because such a high-stakes test determines their future. Their problem is intensified when they are pinched with time and when they have to meet a deadline for admission. They would be successful if they knew what challenges they would face in writing section, what types of mistakes they usually made in their productive attempt, and what sort of feedback contributed to their success.

The researchers are going to find out how a teacher may help students to assuage their worries. The purpose of this research is to make a hierarchically ranked list of mistakes for pedagogical hints. Such a list along with the writing scoring criteria will help both the students and the teachers. Furthermore, the students should know in what area they seriously need correction and the teachers should adopt suitable strategies to help candidates overcome their problems.

In the quest to understand the nature of Communicative Language Ability (CLA) and how second or foreign (L2) language knowledge can be used successfully to communicate a variety of meanings in different social and academic contexts, language testing researchers have proposed an array of theoretical models of L2 ability as a basis for assessment. Some of these models (e.g., Bachman \& Palmer, [4]; Canale \& Swain, [5]; Purpura, [6] explicitly represent the components of the L2 ability construct along with their presumed interrelationships. Examples of knowledge components specified in these models include, among others, grammatical knowledge, lexical knowledge, discourse knowledge, sociolinguistic knowledge, and pragmatic knowledge. All these are part of the knowledge of each skill in the language.

\subsection{Writing Genre}

A genre is characterized by a lot of works sharing the common form, aim, and content. It is important to know the common attributes of each genre. Pasquarelli [7] requires a teacher to consider six types of genre while teaching the writing skill. The first type is descriptive, the purpose of which is to give a vivid and detailed description of a person, place or thing. The second one is expository which is going to give information or explain thoroughly. The third one is narrative which narrates a story of some incidents. Next, a persuasive genre tends to give an idea to persuade the reader to accept an opinion or to take some actions. The fifth genre is poetry which uses language, be it metrical and rhythmical or not, to create a specific atmosphere. Finally, technical genre is to communicate some pieces of information for a specific aim.

The researchers are going to find out what challenges the IELTS candidates take on in the writing skill when they sit such a crucial test. The researches will consider only the second task in IELTS writing module because it is the one in which the candidate should pass his own judgment on a topic and persuade the reader to accept his/her opinion. Furthermore, since it requires a greater amount of linguistic input, it more appropriately represents the learner's ability in the writing skill.

The second task can be both persuasive and informational because the student supports his/her idea by factual information to convince the reader to agree with his opinion. Persuasive writing may employ a vast area of different knowledge such as science, social science, literature, and the dominant political, social, and cultural issues. In this type of writing, the cognitive abilities of the learner, their reasoning prowess in particular, can significantly affect the quality of the process and product of writing.

Another type of essay is the opinion essay. According to Bereiter and Scardamalia [8], there are two major elements involved: statement of belief, which shows the clear stance of the learner, and reasons, 
which show how firmly the learner's stance is supported. This type may include various reasons and counterarguments in a more advanced level of writing. It also requires the writer to give his opinion without any extrinsic information. That is, he/she needs just his/her own personal beliefs which are quite subjective.

Some scholars (Calkins, [9]; Graves, [10]; Weaver, [11]) believe that a good writer is expected to to take into account three components for rendering a piece of writing: a) the process of writing such as planning, writing, and revising, which constitute the foundation of the writing; b) the conventions of a language (syntax, spelling and punctuation), which carry the propositional layer of the work; and c) the essence of each writing genre which is a function of the content, purpose and audience of the writing.

Pasquarelli [7] asserts that an instructor will follow all these elements in a cohesive process while teaching one specific genre. In other words, a student can learn how to use mechanical and grammatical points meticulously while learning one writing genre. Consequently, the researchers are determined to work just on one writing genre: opinion essays.

Teaching the writing section, the researchers tend to employ the same strategies which Pasquarelli [7] did: prewriting, drafting, revising, editing, publishing. The first step is prewriting. Here, the writer determines what he/she writes, who will read his essay (the audience), what his aim is, and in what form he/she presents his materials. At this stage, brainstorming can be particularly useful.

The next step is drafting which is semantically, not syntactically, oriented. In other words, the writer is concerned just about content, not about grammar. The third stage is revising, the major concern of which is to clarify content, organization, and style, again without considering mechanics and grammar. Here he/she may re-read his/her piece many times to remove any possible problem. He/she may also ask some people to read the text so that he/she can understand whether it is intelligible or not. The final stages are editing and publishing. At this stage, he/she pays attention to the structure, punctuation, and spelling which should be done first by himself/herself, and then he/she can ask peers to edit the piece.

\subsection{High-stakes tests}

In Iran, two high-stakes tests, TOEFL or IELTS, are administered. It is essential for Iranian students who wish to pursue their study abroad to get a high score on such tests to be admitted by foreign universities. These tests are also required to be taken by those who intend to immigrate to a foreign country in which English is the primary language of communication. For this reason, they are highly motivated to do well on these exams to have eligibility.

In the Writing section of the IELTS, students employ many skills and techniques to communicate when doing specific tasks. It includes a range of activities such as planning, setting goals, managing time, organizing and prioritizing. Therefore, a learner is expected to know different strategies to accomplish the task successfully.

\subsubsection{What is IELTS?}

The International English Language Testing System (IELTS) is an English language proficiency test codeveloped by the University of Cambridge, British Council and IDP: Australia. There are two types of IELTS: Academic module for those students who intend to pursue their study and the General module for those people who plan to apply for immigration. In both tests, Listening and Speaking are the same, but Reading and Writing sections are different. In writing section 1, the Academic candidates are required to describe charts and other types of visual information. However, the General candidates must write a letter on general social or everyday life issues with particular audience. 
This research shows that IELTS candidates have to improve their English to do well on this exam and the high score they get can be valid for the real life in a foreign country or let them continue their study in higher education.

\section{METHODOLOGY}

\subsection{Participants}

Sixty seven IELTS and TOEFL students were asked to fill out an open-ended questionnaire to find out what challenges they have when they write in English, in general, and what makes high-stakes writing component difficult, in particular. Twenty four of the participants were then interviewed to have an indepth analysis of their challenges.

\subsection{Instrument}

An open-ended questionnaire was used to find out what the students found most difficult in writing and what they specifically found differently difficult in writing for IELTS and TOEFL.

\subsection{Procedure}

The sixty seven learners were given an open-ended questionnaire to write what they thought made writing difficult. To have a thorough understanding of what they thought was making writing difficult, the researchers then interviewed twenty four of the participants.

\section{RESULTS}

The sentences here are reported intact. The researchers thought the verbatim report of what the participants said would give a clearer idea of what the participants wrote or said. The findings after the analysis of the questionnaires and the interviews suggest that the topic, vocabulary, grammar, choice of words, spelling, cultural issues, general knowledge, comprehensibility of what they have written, elaboration of the topic, organization, amount of practice, word count, the allotted time and affective matters are what make writing difficult. Therefore, to improve our writing, we should work on all these areas. Some of the terms which the students used were not the ones mentioned above but the researchers used the more technical terms to make it more understandable. In the following case, we used the term organization for "a methodology for writing". S2 put:

"Also, the methodology of writing is important. If you do not know it, you can not develop your idea very good."

Vocabulary and grammar are believed by most of the students to be the most problematic areas in writing. S5, S12, S13, S19, S29, S45, S48, S52, S60 respectively put forth their ideas as follows:

"In addition to I have many problems with grammar of that language also."

"... you need to use correct grammar and vocabulary and even spelling."

"The problem of not having an extensive repertoire of vocabulary of the target language, or not being aware of the grammatical rules are the most common ones."

"Most of people have some issues like ... not knowing the organization or grammar rules." 
"As vocabulary source is limited, so the disability to clarify our meaning maybe another problem, grammatical rules shall be followed too, ..."

"Lack of vocabulary, ... , daily words are the most important reasons for difficulty of writing."

"... the breadth of my vocabulary is not vast and there is a limit to what I can write in English."

"Regarding writing in a second language, I found it more difficult than writing in my mother tongue. And I think it is natural because I may find problems using the correct grammar and vocabulary."

"My major problem is how to use words. The words exactly used by the native speakers usually make some problems for me. The second problem is that I don't have a superb command of structural rules. In my own language, for, example, a verb is used at the end of the sentence but in English a verb follows the subject."

Mechanical errors seem to be important to some. They believe it could be a source for the difficulty of writing: S43, S47, S55, S61:

"Besides, my spelling is terrible."

"I am always doubtful when I write a word and usually as I change the dictation, it becomes worse. As a result, I prefer to choose another word and that makes it difficult and somehow tedious to me."

"sometimes I don't know where to break a sentence and use a period and start a new one."

"I am obsessed with punctuation. I think that I will not get a high score if I make some mistakes in punctuation."

One thing that some students mentioned was the amount of reading. S31, S39, S49 and S61 believed:

"Finally and foremost, I can't organize my essay and I am always distracted in the middle of my writing. I can't support my topic sentences and my reasons usually are not convincing or they are not relevant to my topic."

"In my opinion, most of the people use only limited words for their writing and it causes from lack of reading books. Today, minority of people read the books, magazine and newspaper."

"We should also read so many books in order to have an organized mind."

"I believe that reading different texts can help us get acquainted with different styles, different English structures and at the same time it can help us get information about different topics which can help us to have enough background about the given writing topics."

When asked why, S61 thought, reading organizes the mind, she said:

"Because you might not be able to support what you say well. If you do not know the topic or have never heard anything about the topic, you might not be able to support it."

Topic knowledge was also one of the most problematic areas in writing. S6, S19, S27, S32, S45, S51 mentioned that they found topic as one of the most crucial factors contributing to the ease or difficulty of 
writing. They believed that if the topic is within their realm of knowledge, they could easily write about it and elaborate on it. However, if it is something they were not familiar with, that would be impossible to put even a few words together.

"... we have to talk about the topic but we don't have many ideas to talk about it."

"I, myself, think that the topic of the subject that we want to, or have to write is really important. Because whenever the person who wants to write, has lots of information about the topic, so it would be more easier for him/her to compose an article due to the topic, rather than a person who hasn't ever heard any thing about that."

"According to my opinion, what makes writing difficult ... is the topic we have to write about ... When we are offered, as for example, a philosophic topic or very special to write about, then to write would be very difficult."

"The lack of knowledge about the topic is one of them."

"The most important matter ... can appear to us is the lack of information about related topic."

“... there is possible he doesn't understand the topic thoroughly."

Elaboration of ideas was not mentioned by a lot the participants but clearly because it is one of the criteria for the correction their written piece, it deserves some kind of minimal attention at the very least. S12 and S65.

"I think writing in English is difficult because I can't wide my subject and tell what I really want to say so with this problem writing in second language is more difficult to me."

"Iranian students usually fail to develop the main idea with reasoning, explanation, and examples. They can never give any example in their arguments even if they use some connecting words such as 'for example'."

Amount of practice was also mentioned by some to be of importance. In this case, it is believed the more we write, the better writing we will produce. S18 and S63:

"Writing in second language need so many skills. To improve our writing we should write more and more read so many books and ..."

"The students usually require their teacher to read as many essays as possible because in this way they can wrote better."

In terms of writing, some said that they found writing in English easier than writing in Persian. In one special case, one student even said that he thought some structures are formal, whereas others are not. Like S56 said:

"Although this is my second language and I used it less than my mother one. But as I studied more literature or papers or books to be familiar with it I know formal structures than informal, so in some case it would help me."

The affective domain was what some considered very important. The teachers some believed will have to do something so the students will feel like writing rather than feel obliged to do so. S56, S59, S67 said: 
"Actually, I hate writing. In primary school when my teacher told us to write, I became sad and requested my mother to write."

"I dread writing and it does not really matter what I am supposed to write. Writing is disgusting."

"I have not written even one essay during my twelve-year education. When I am required to write for the first time in the second language, it makes it impossible to get even a few words on the paper."

When it comes to writing for TOEFL and IELTS, the students did not say that they felt it was much different but for three major things. The students find the time limitation, word count and the stress they are under. In terms of TOEFL, one student mentioned that typing in English was also difficult. S5, S34, S42, S65 said:

"In addition, when I am writing in the comfort of my bedroom and have a lot of time, I feel ok but when I am writing for a test and then they limit me with the stupid idea of the number of words and time, my mind goes blank."

"Thinking about a topic at a limited time and finding some relevant sentences is hard."

"Generally, writing is difficult for me; in my mother tongue or other language. Because thinking about a topic at limited time and finding some sentences about that is hard. Actually, concentration on something is not easy for me. I need long time for thinking about special topic and then writing about that."

"I wish I did not have to type. It is very difficult to type in English."

Something which was mentioned while writing in second language was the use of mental translation. This meant that the students had to think in their mother tongue and then translate the mother tongue into $\mathrm{L} 2$. S12, S27, S35 and S66 respectively said:

"... So in my opinion what we should write and what we should discuss is one problem and translate it to second language is another."

"But in addition we have to mentioned that, because most the people think in their mother tongue language and translate it to other languages through their vocabulary capability, so we can deduce that this translation process can slow down the speed of writing."

"...So in my opinion what we should discuss is one problem and translate it to second language is another."

“...he/she is thinking about the topic in his/her mother tongue and translates it into second language."

The formality of writing compared to speaking was another realm mentioned by some three participants, namely S46, S57 and S58.

"So, if a non-native is familiar with, not only the grammar, but also the common spoken and written forms of a second language, she/he could probably be able to write something as correct and beautiful as a native." 
"I also believe that not every native is concerned about his mother language. In other words, as they have learned well their first language in spoken form, and without any problem they are able to communicate in their daily life, they mostly won't care about the written form, grammar, and written mistakes.

"the other reason is when a person have to write formally and his/ her vocabulary must be not impolite and must be formal."

Cultural issues are also considered, though by a few, to be an area which could add to the complexity of writing in the second language. If the candidates are not culturally familiar with the topic, they find it mentally demanding; hence, impossible to write about. S38 and S64:

"Another difficulty is that you may found that the topic is very far from your own culture. For example consider topic that is asked a Christian to write about ritual creed or funeral ceremony of Bodiahen. Since it is not part of his culture again he cannot write cohesively."

"One of the most problematic things, in terms of writing in a different language, is that you are not quite familiar with the mindset of the people of that country. In a country like Iran people are not sensitive to some issues which might be of importance in western countries. I remember once I was asked to write about keeping pets which was quite a demanding task for me."

\section{CONCLUSION}

The findings, among others, suggest that high-stakes tests exert so much pressure on the candidates because that their future rests in their performance in such tests. Should they fail to perform as well as they are expected to, they might have to take the Hobson's choice.

\section{REFERENCES}

[1] Brown, H. D. (2001). Teaching by principles: An interactive approach to language pedagogy (2nd ed.). NY: Longman.

[2] Nunan, D. (1999). Second language teaching and learning. Boston: Heinle \& Heinle Publishers.

[3] Winer, L. (1992). "Spinach to chocolate" :Changing awareness and attitudes in ESL writing teachers. TESOL Quarterly, 26, 57-80.

[4] Bachman, L. \& Palmer, A. (2010). Language assessment in practice. Oxford: OUP.

[5] Canale, M., \& Swain, M. (1980). Theoretical bases of communicative approaches to second language teaching and testing. Applied Linguistics, 1, 1-47.

[6] Purpura, J. (2008) Assessing Communicative Language Ability: Models And Components, in Shohamy, E. and Hornberger, N.H. (eds.), Encyclopedia Of Language And Education, Volume 7: Language Testing And Assessment, $2^{\text {nd }}$ Fully Revised Ed. New York: Springer.

[7] Pasquarelli, S. L. (2006). Teaching writing genres across the curriculum: Strategies for middle school. CT: Information Age Publishing. 
[8] Bereiter, C., \& Scardamalia, M. (1987). The psychology of written composition. Hillsdale, NJ: Erlbaum.

[9] Calkins, L. M. (1994). The art of teaching writing. Portsmouth, NH: Heinemann.

[10] Graves, D. H. (1983). Writing: teachers and children at work. Exeter, NH: Heinemann.

[11] Weaver, C. 919960. Teaching grammar in the context of writing. English Journal, 85, 15-24. 